\title{
Different responses to mechanical injury in neonatal and adult ovine articular cartilage
}

\author{
Xuhong Xue, Qixin Zheng, Hongbin Wu', Lixue Zou and Peng Li
}

\author{
* Correspondence: hongbinwulj@ \\ 163.com \\ Department of Orthopedics, Union \\ Hospital, Tongji Medical College, \\ Huazhong University of Science and \\ Technology, Wuhan 430022, China
}

\begin{abstract}
Background: Articular cartilage injury remains a major challenge in orthopedic surgery. This study aimed to identify differences in gene expression and molecular responses between neonatal and adult articular cartilage during the healing of an injury.

Methods: An established in vitro model was used to compare the transcriptional response to cartilage injury in neonatal and adult sheep by microarray analysis of gene expression. Total RNA was isolated from tissue samples, linearly amplified, and 15,208 ovine probes were applied to cDNA microarray. Validation for selected genes was obtained by real-time quantitative polymerase chain reaction (RT-qPCR).

Results: We found 1,075 (11.6\%) differentially expressed probe sets in adult injured cartilage relative to normal cartilage. A total of 1,016 (11.0\%) probe sets were differentially expressed in neonatal injured cartilage relative to normal cartilage. A total of 1,492 (16.1\%) probe sets were differentially expressed in adult normal cartilage relative to neonatal normal cartilage. A total of 1,411 (15.3\%) probe sets were differentially expressed in adult injured cartilage relative to neonatal injured cartilage. Significant functional clusters included genes associated with wound healing, articular protection, inflammation, and energy metabolism. Selected genes (PPARG, LDH, TOM, HIF1A, SMAD7, and NF-KB) were also found and validated by RT-qPCR.
\end{abstract}

Conclusions: There are significant differences in gene expression between neonatal and adult ovine articular cartilage following acute injury. They are partly due to intrinsic differences in the process of development, and partly to different biological responses to mechanical trauma between neonatal and adult articular cartilage.

Keywords: Cartilage, Microarray, Mechanical injury, Neonatal, Ovine, Differential gene expression

\section{Background}

Articular cartilage injury remains a major challenge in orthopedic surgery. This may be mainly due to the specific morphological structure of articular cartilage [1]. Articular cartilage is a highly ordered, specialized connective tissue, which provides a smooth surface and low friction weight-bearing support used for protection of joints by absorbing mechanical stresses and loads [2]. Traumatic cartilage injury leads to an irreversible cartilage loss because differentiated chondrocytes do not divide, and therefore, do not compensate for these defects. Previous studies have reported that posttraumatic articular cartilage in adults is often fibrous cartilage or hyaline-like cartilage

(c) 2013 Xue et al.; licensee BioMed Central Ltd. This is an Open Access article distributed under the terms of the Creative Commons Attribution License (http://creativecommons.org/licenses/by/2.0), which permits unrestricted use, distribution, and reproduction in any medium, provided the original work is properly cited. 
of which the biological properties and mechanical strength are inferior to normal cartilage [3]. However, the results from a clinical study indicated that acute full-thickness joint surface defects show the potential for intrinsic repair in young individuals [4]. Similarly, spontaneous repair of relatively small, experimental, full-thickness joint surface defects in animal models has been reported [5]. Spontaneous repair can be complete in a fetal lamb articular cartilage superficial defects model [6].

The different mechanisms of cartilage repair in young and adult articular cartilage are unclear. Changes at the molecular level, consisting of key genes or signaling pathways, may occur during the developmental process, and this might lessen the repair ability of articular cartilage.

This study compared the transcriptional response to cartilage injury in neonatal and adult sheep. This study aimed to identify the portion of gene regulation associated (and perhaps responsible for) successful healing. Our findings could be important for designing instruments to induce cartilage repair.

\section{Methods}

\section{Ex vivo cartilage injury model and tissue culture}

Articular cartilage explants were harvested from adult $(n=3,2$ years old) and neonatal sheep ( $n=3$, 1 week old) bilateral femoral medial condyle. These animals were housed in the animal center of the Tongji Medical College, Huazhong University of Science and Technology. The study was approved by the Ethical Committee for Animal Experiments of Tongji Medical College, Huazhong University of Science and Technology.

The experimental design of cartilage injury was as follows: adult experiment (injury) versus adult control (normal); neonatal experiment (injury) versus neonatal control (normal); adult experiment (injury) versus neonatal experiment (injury); and adult control (normal) versus neonatal control (normal). Cartilage explants were washed in phosphate-buffered saline and maintained in a culture medium as previously described [7], containing Dulbecco's modified Eagle's medium /F12 (Invitrogen) in the presence of $10 \%$ fetal bovine serum (Invitrogen), and 100 units $/ \mathrm{ml}$ penicillin and streptomycin (Invitrogen) in a six-well culture plate at $37^{\circ} \mathrm{C}$ in a humidified $5 \% \mathrm{CO}_{2}$ atmosphere. The medium was changed every other day, and after 6 days, the medium was removed. Our model of cartilage injury is summarized in Figure 1A. Cartilage explants at left side were dissected onto a $2 \times 2 \mathrm{~mm}^{2}$ grid (horizontal and vertical at 2 -mm intervals) using a scalpel. Care was taken to avoid contamination by blood, bone, or synovium. The explant at right side was used for control samples. After $24 \mathrm{~h}$, articular cartilage explants were shaved from the joint surfaces and preserved in liquid nitrogen for later RNA extraction.

\section{Histology}

Samples were also collected and prepared for histological analyses as described by Frisbie et al. [8]. Briefly, normal articular cartilage tissue and injury were fixed in $10 \%$ neutral buffered formalin for a minimum of 2 days. Samples then had $0.1 \%$ EDTA/3\% $\mathrm{HCl}$ decalcification solution added, which was replenished every 3 days until specimens were decalcified. Specimens were embedded in paraffin and sectioned at $5 \mu \mathrm{m}$. Sections were stained with hematoxylin and eosin. 


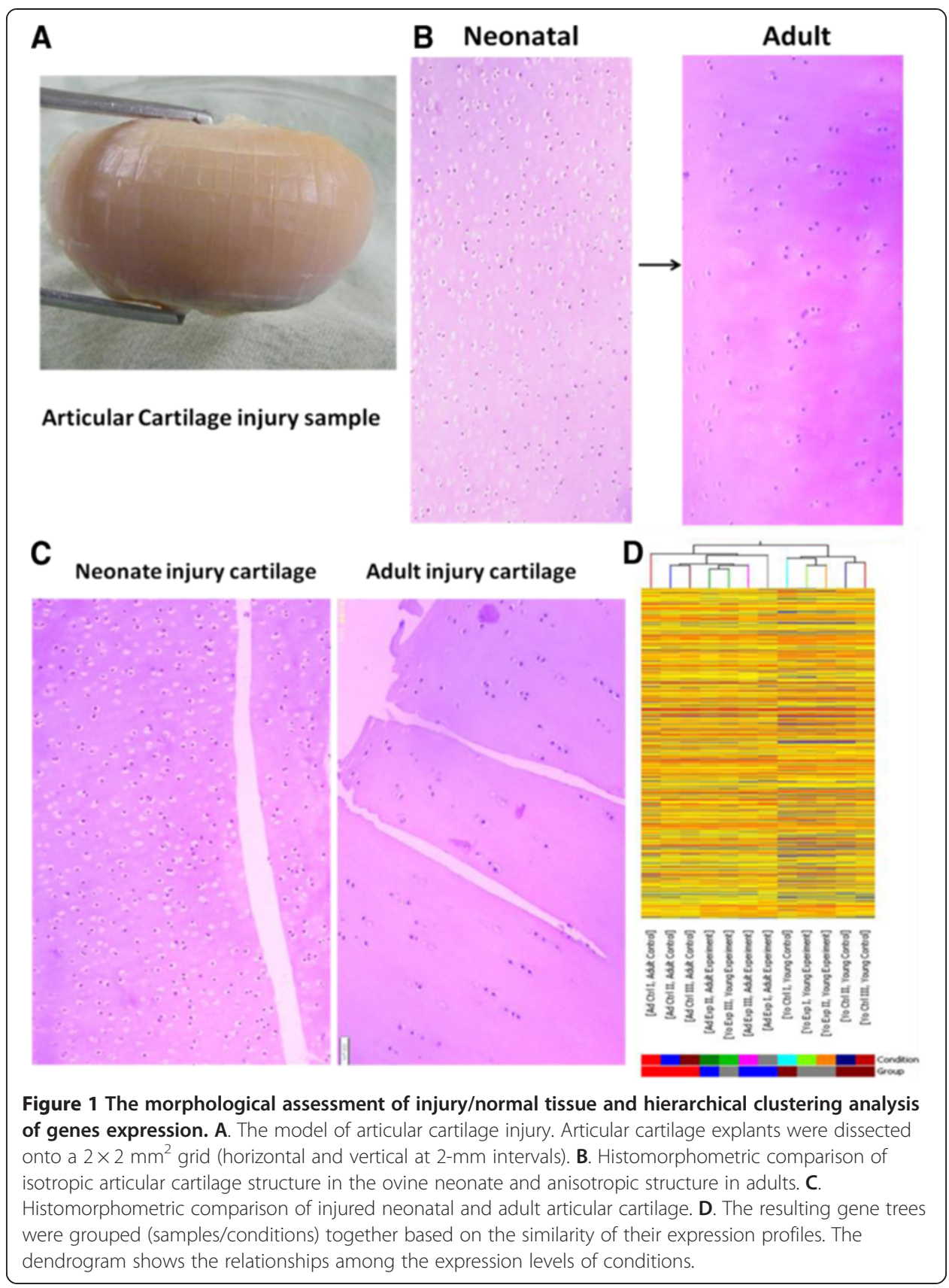

\section{Total RNA extraction}

Total RNA was isolated as described by Dell'Accio et al. [7]. Briefly, each frozen explant was pulverized using a mortar and pestle pre-chilled in liquid nitrogen, suspended in $4 \mathrm{ml}$ of TRIzol reagent (Invitrogen), and homogenized using a Mini-Bead-Beater-16 (Biospec). This was followed by differential alcohol and salt precipitations, and then final purification was performed using the Qiagen RNeasy Mini Kit by following the manufacturer's protocol. RNA quantification and quality assurance were tested by NanoDrop-1000. Purity and integrity were assessed using the Agilent 2100 Bioanalyzer. The RNA quality was selected for microarray analysis of gene expression and quantitative real-time polymerase chain reaction (RT-qPCR). 


\section{Microarray analysis}

Total RNA from each tissue sample was amplified and labeled using the Agilent Quick Amp labeling kit, and hybridized with the Agilent whole genome oligo microarray in Agilents SureHyb hybridization chambers [9]. After hybridization and washing, the processed slides were scanned with a DNA microarray scanner (Agilent, part number G2505B) using settings recommended by Agilent Technologies. Feature Extraction software (version 10.5.1.1) was used to assess fluorescent hybridization signals and to normalize signals using linear regression and a Lowess curve-fit technique. Reproducibility and reliability of each single microarray were assessed using quality control report data (Feature Extraction software, version 10.5.1.1).

\section{Quantitative real-time RT-qPCR}

Quantitative real-time RT-PCR was performed as described previously [7]. Gene expression was calculated using a standard curve and was normalized to the expression of the housekeeping gene glyceraldehyde-3-phosphate dehydrogenase (GAPDH). Purified RNA was reversely transcribed into cDNA using Superscript II RT (Invitrogen). Equivalent amounts as calculated by the initial RNA quantity were added to the reaction mix including $12.5 \mathrm{ml}$ SYBR Green (Invitrogen), forward and reverse primers (10 $\mathrm{pmol} / \mathrm{ml}$ ), with $0.5 \mathrm{ml}$ for each primer, and nuclease-free water to final volumes of $25 \mathrm{ml}$ per well. Primer sequences are listed in Table 1. Real-time RT-PCR was run in an ABI Prism 7700 Sequence Detection System (SDS) using the ABI Prism 7700 SDS software version 1.2.3.

\section{Statistical analysis}

The 12 microarray data sets were normalized in GeneSpring GX (version 11.0) using the Agilent FE (version 10.5.1.1) one-color scenario (quantile normalization). The entities were filtered based on their flag values of $\mathrm{P}$ (present), $\mathrm{M}$ (marginal), and A

Table 1 Primer nucleotide sequences used in quantitative real-time RT-qPCR assays for genes described in the study

\begin{tabular}{|c|c|c|c|}
\hline Gene name & $\begin{array}{c}\text { Gene } \\
\text { symbol }\end{array}$ & Primer sequences & $\begin{array}{l}\text { Ampliconsize } \\
\text { (bp) }\end{array}$ \\
\hline \multirow[t]{2}{*}{ glyceraldehyde-3-phosphate dehydrogenase } & \multirow[t]{2}{*}{ GAPDH } & F:5'GTTCCACGGCACAGTCAAGG3' & \multirow[t]{2}{*}{117} \\
\hline & & R:5TACTCAGCACCAGCATCACCC3' & \\
\hline \multirow{2}{*}{$\begin{array}{l}\text { mothers against DPP (Drosophila)human } \\
\text { homologue } 7\end{array}$} & \multirow[t]{2}{*}{ SMAD7 } & F:5'ACAACCGCAGCAGTTACCC3' & \multirow[t]{2}{*}{129} \\
\hline & & R:5TGTACGCCTTCTCGTAGTCAA3' & \\
\hline \multirow{2}{*}{$\begin{array}{l}\text { peroxisome proliferator-activated receptor } \\
\text { gamma }\end{array}$} & \multirow[t]{2}{*}{ PPARG } & F:5'GCGACATCGACCAACTGAAC3' & \multirow[t]{2}{*}{274} \\
\hline & & R:5'ACGGAGCGAAACTGACACC3' & \\
\hline \multirow[t]{2}{*}{ thappin ovine molecule } & \multirow[t]{2}{*}{ TOM } & F:5'CCAGGTGGTGGTGCTTCTC3' & \multirow[t]{2}{*}{127} \\
\hline & & R:5'ACCGTTGATTGGACCCTIT3' & \\
\hline \multirow[t]{2}{*}{ nuclear factor-kappa B } & \multirow[t]{2}{*}{ NFKB } & F:5'ACGAGGATGATGAGAATGGATG3' & \multirow[t]{2}{*}{135} \\
\hline & & R:5'GCAGGAACACGGTTACAGGAC3' & \\
\hline \multirow[t]{2}{*}{ lactate dehydrogenase } & \multirow[t]{2}{*}{ LDHA } & F:5'GGGACAGAATGGAATCTCAGAC3' & \multirow[t]{2}{*}{296} \\
\hline & & R:5TTGCCATCCAGCAGGGT3' & \\
\hline \multirow[t]{2}{*}{ Hypoxia-inducible factor-1a } & \multirow[t]{2}{*}{ HIF1a } & F; 5'-CGAAGAACTCTCAGCCACAG-3' & \multirow[t]{2}{*}{174} \\
\hline & & R:5'-AGCTCGTGTCCT CAGATTCC-3' & \\
\hline
\end{tabular}


(absent). Only entities having the present and marginal flags in at least one sample are displayed in the profile plot.

Only genes with values exceeding background intensity in at least three samples of either condition for each comparison were used for two-way analysis of variance (ANOVA) with the least significant difference (LSD) t-test, which were followed by Benjamini and Hochberg correction based on a false discovery rate of $2.2 \%$ for probe sets with a $p$-value $<0.01$ [10]. Volcano plots were used to filter for genes differentially expressed by $\geq 2$-fold and with $p<0.05$. Unsupervised hierarchical clustering analysis was performed on this subset of genes.

For quantitative real-time RT-PCR, the gene expression ratio between every two groups was determined and analyzed using SPSS version 17.0 (SPSS Inc., Chicago, IL, USA).. The relative expression levels in every two compares for the selected genes were normalized to the endogenous reference gene GAPDH by using the formula $2^{\text {-Ct target }}$

$2^{-\mathrm{Ct} \text { GAPDH }}$, where $\mathrm{Ct}$ is the threshold cycle. All data are expressed as mean \pm standard deviation. Differences were considered significant at $p<0.05$.

\section{Results}

\section{Articular cartilage histology}

Tissue samples were harvested $24 \mathrm{~h}$ after injury induction of full-thickness cartilage lesions. Gross histomorphometric examination showed the transition from isotropic to anisotropic architecture in neonatal and adult ovine articular cartilage (Figure 1B). Histologically, lesion tissue generally had a homogeneous matrix architecture with elongated, flattened cells that interfaced with surrounding articular cartilage. Each lesion was dimpled in appearance and not completely level with the articular surface (Figure 1C).

\section{Overall level of differential gene expression and annotated genes}

Of the 15,208 gene probes, 9,252 probe sets were present in the PMA. Further analyses were carried out on these probe sets. Based on a $p$-value of $0.05,1,075$ (11.6\%) probe sets were differentially expressed in adult injured cartilage relative to normal cartilage, $1,016(11.0 \%)$ probe sets were differentially expressed in neonatal injured cartilage relative to normal cartilage, 1,492 (16.1\%) probe sets were differentially expressed in adult normal cartilage relative to neonatal normal cartilage, and 1,411 (15.3\%) probe sets were differentially expressed in adult injured cartilage relative to neonatal injured cartilage in each pair of samples (Figure 2).

After Benjamini and Hochberg correction to compare gene expression in the four groups, 1,070, 1,005, 1,082, and 1,401 probes were identified as being significantly $(p<0.05)$ altered in each group. The estimated false discovery rate was $0.47,1.1$, 0.8 , and $0.7 \%$, respectively (Figure 2). A volcano plot shows that 86 and 83 genes were significantly regulated at least 2-fold post-injury for neonatal sheep (Figure $3 \mathrm{~B}$ ) and adult sheep, respectively (Figure 3A). A total of 132 probe sets were upregulated (Figure 3D) in neonatal injured articular cartilage relative to adult articular cartilage. A total of 185 probe sets were up-regulated in adult injured articular cartilage relative to neonatal articular cartilage (Figure 3D). Comparative transcription profiling and gene annotation in each pair are listed in Table 2. 


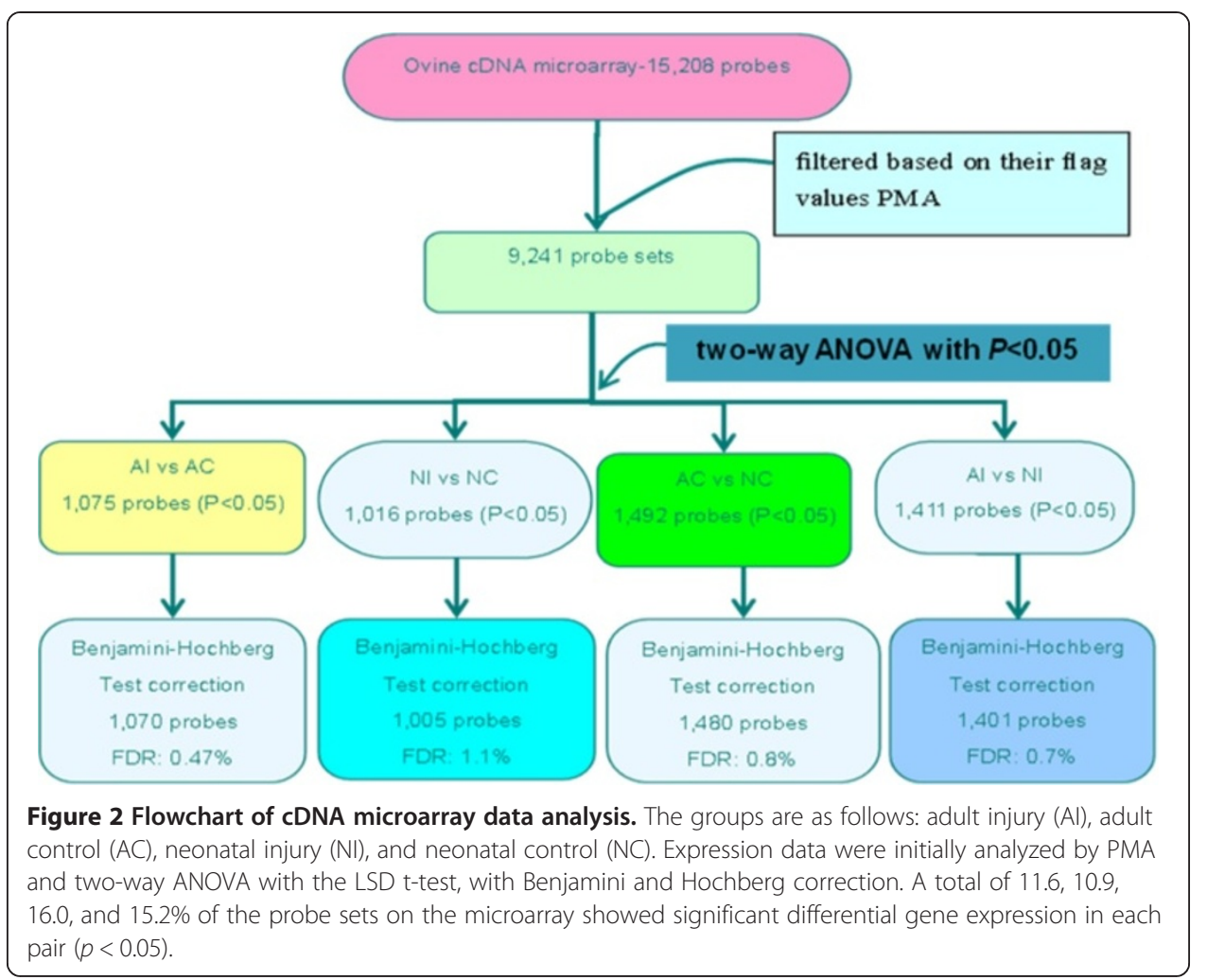

Among the 825 differentially expressed genes in total, 62 corresponded to known genes with a unique identifier, and sourced from RefSeq and UniGene. The expression of annotated genes in each pair is shown in Table 3.

\section{Hierarchical clustering analysis}

To investigate how gene expression varied across the samples, we performed hierarchical clustering analysis. In this analysis, samples were grouped according to their expression profile based on all genes, whether or not the genes were differentially expressed in the experimental (injured) versus the control (normal) group. A dendrogram shows the relationships among the expression levels of conditions. Our experiment consisted of 12 different conditions. The results of hierarchical clustering based on conditions showed a distinguishable gene expression profiling among samples (Figure 1D). Significant functional clusters included genes associated with wound healing, articular protection, repair integration, and energy metabolism. Such transcripts, including peroxisome proliferator activated receptor $\gamma(\mathrm{PPAR} \gamma)$, trappin ovine molecule (TOM), mothers against DPP (Drosophila) human homolog 7 (SMAD7), nuclear factor-kappa B (NF-кB), hypoxia inducible factor- $1 \alpha$ (HIF1- $\alpha$ ), and lactate dehydrogenase (LDH) were regulated in their respective direction (up- or down-regulated) according to their change with tissue maturity/age and injury (Figure 3).

\section{Results by quantitative real-time RT-PCR}

Quantitative real-time RT-PCR was performed on the six up-regulated genes to validate the microarray results, including PPAR $\gamma$, LDH, TOM, HIF1A, SMAD7, and NF-kB, 


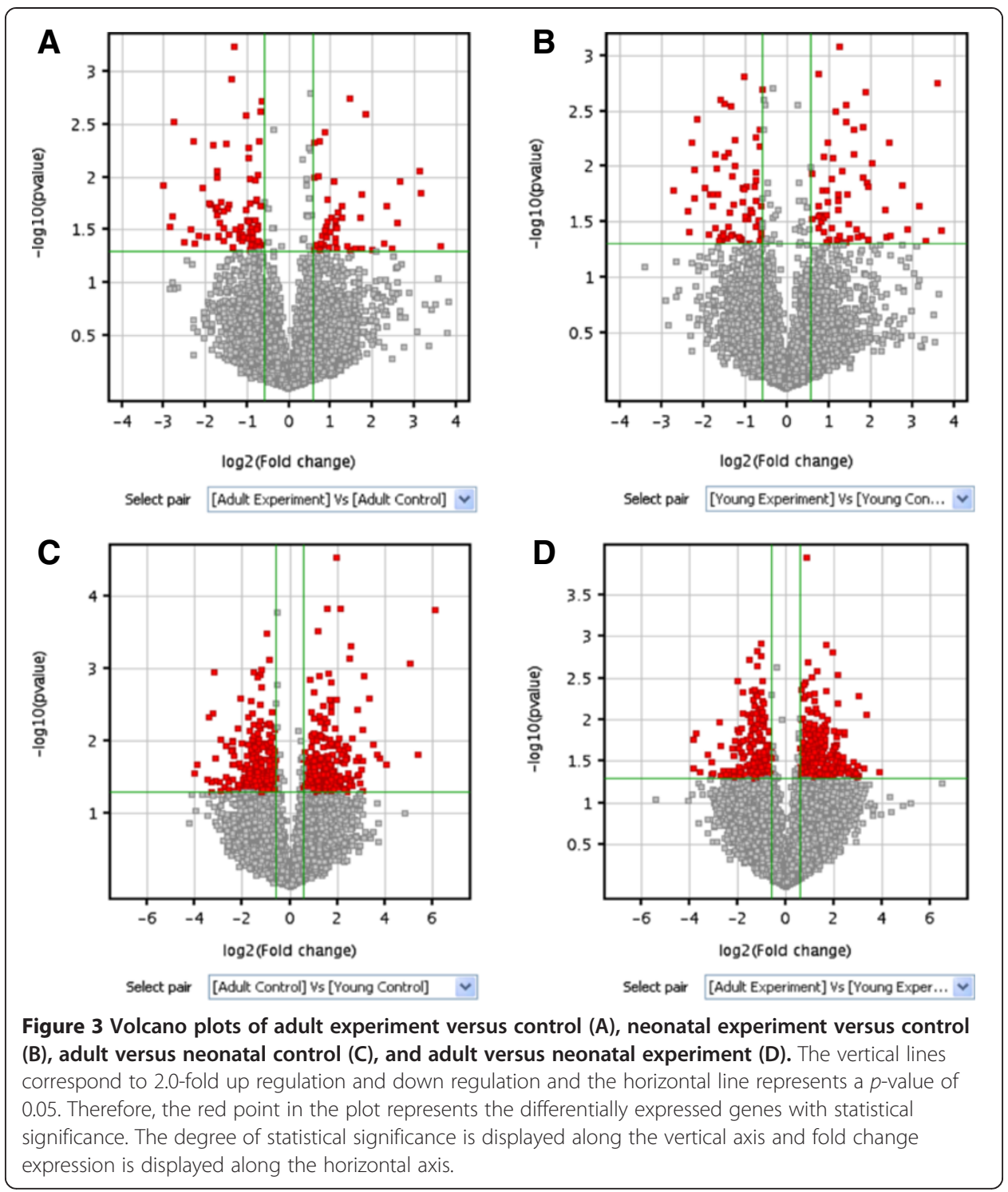

which were associated with wound healing, articular protect, inflammation and energy metabolism according to literature [11-13]. We found a significant increase in mRNA abundance for PPAR $\gamma$ and TOM in neonatal injured articular cartilage (Figure 4). Fold change differences were similar or slightly greater than those measured by microarray profiles. In general, the quantitative real-time RT-PCR and microarray data agreed well for most samples, emphasizing the robustness of the microarray data.

\section{Discussion}

Traumatic cartilage lesions represent a common symptomatic and disabling problem, which often requires surgical intervention to relieve pain and to prevent possible evolution towards secondary osteoarthritis [14]. In the present study, an ovine agedependent ex-vivo articular cartilage model following acute injury was developed and 
Table 2 Comparative transcription profiling between the every two groups

\begin{tabular}{|c|c|c|c|c|}
\hline Group & $\mathrm{Al} / \mathrm{AC}$ & $\mathrm{NI} / \mathrm{NC}$ & $\mathrm{AC} / \mathrm{NC}$ & $\mathrm{Al} / \mathrm{NI}$ \\
\hline up-regulation & 32 & 190 & 185 & 44 \\
\hline \multirow[t]{7}{*}{ Annotated genes } & CENP-C,LDHA,TNC, & ESR1, NF-KB, OVAR, & FZD3, NFkB1A, NOD2 & SMAD7, TF, PPARG, \\
\hline & DCN,TNFa,IL-1 $\beta$ & PRKAR1A,PBR, EF-1, & MMP7, CAT-1, RAC-1 & ERBA BETA, GRO, \\
\hline & & MIF, HIF1A, SPRY-4, & CP, C-MET, CENP-C & IL-1 $\beta, T N F$, IGFBP2, \\
\hline & & ALDOA,CD40,PSMB8, & CAST, F11R, FAS & FCER1G \\
\hline & & ERBA BETA,COL1A1, & & \\
\hline & & BBC-1,FGF10, FBLN, & & \\
\hline & & FAS, CPE, NOS2, CAST & & \\
\hline down-regulation & 50 & 150 & 132 & 42 \\
\hline \multirow[t]{4}{*}{ Annotated genes } & SIN1,COL2A1,FN & COL2A1, TXN, TNCC2, & VDUP1, BACT2, TOM & COL1A1,PPP1R12A, \\
\hline & HECTD1 & OXT,TNC, TOM, HBB, & LDHA, PSMB7, G6PD, & SMCT1, IGF2, CD1D \\
\hline & & PTGS1, IRF2, PSMB7, & SMAD7, CD1D, SIN1, & SFN \\
\hline & & G6PD, CAT-1,CHID & HOXA7, HIF-1A & \\
\hline
\end{tabular}

Notes:Adult Injury(AI), Adult Control(AC), Neonate Injury(NI), Neonate Control(NC). Fold Change $\geq 2.0 ; P<0.05$.

characterized. Three pairs of adult and neonatal sheep articular cartilage were detected by CDNA microarray and validated by real time RT-PCR.

The repair of joint surface lesions largely depends on their size and depth $[15,16]$, and the reproducibility of the injury is an important concern. With regard to the choice of the time course of post-injury, Lee et al. showed that the expression of specific catabolic and anabolic genes that regulate matrix remodeling and turnover after mechanical injury within $24 \mathrm{~h}$ is the most significant [17].

Differential gene expression in equine articular cartilage maturation was studied by Mienaltowski et al. [18]. However, the use of microarrays has not been reported in different developmental stages of ovine articular cartilage. In the present study, the up-regulation of collagen type II (COL2A1) and tenascin-C (TNC) was observed in neonatal articular cartilage, while transcripts encoding matrix proteins and growth factors were more abundant in adults, including collagen type I (COL1A1), decorin, and fibroblast growth factor 10. The current data are consistent with previous findings in horses and humans $[18,19]$.

In adult injured articular cartilage versus normal articular cartilage, five annotated genes were significantly up-regulated. In contrast, the expression of four genes was slightly down-regulated. In particular, centromere protein- $C$, insulin growth factor binding protein 2, and LDH have not been previously linked to an imbalance of damage and repair in osteoarthritis, whereas, TNC and COL2A1 have already been reported [18].

Neonatal ovine lesional cartilage and normal articular cartilage were compared in this study. As expected, with the pattern of activation of inflammation and apoptosisrelated genes broadly comparable to those reported in the adult [1], neonatal injured articular explants also had high levels of gene expression, such as interleukin $1 \beta$ (IL-1 $\beta$ ), tumor necrosis factor- $\alpha$, growth-regulated oncogene $\alpha$ (GRO $\alpha)$, and NF-kB.

In our study, transcripts encoding cartilage macromolecules and nuclear receptors, which play a role in cell-cell and cell-matrix interactions, tissue remodeling, and repair, were significantly more abundant in neonatal lesional articular cartilage compared with 
Table 3 Different expression of annotated genes between the every two groups

\begin{tabular}{|c|c|c|c|c|c|c|}
\hline Gene symbol & $\mathrm{Al} / \mathrm{AC}$ & $\mathrm{NI} / \mathrm{NC}$ & $\mathrm{AC} / \mathrm{NC}$ & $\mathrm{Al} / \mathrm{NI}$ & Gen bank accession & UniGene \\
\hline SMAD7 & - & $2.36^{*}(0.025)$ & - & $2.04^{\#}(0.040)$ & EE805013 & Oar.1034 \\
\hline FCER1G & - & $3.16^{*}(0.037)$ & - & - & AJ318335 & Oar.1043 \\
\hline CD1D & - & $3.14^{\#}(0.018)$ & - & $3.04^{\#}(0.047)$ & NM_001123001 & Oar.1049 \\
\hline G6PD & - & - & $2.75^{\#}(0.016)$ & $3.70^{\#}(0.042)$ & NM_001093780 & Oar.1073 \\
\hline$E F-1$ & - & - & $2.82^{*}(0.036)$ & - & NM_001009449 & Oar.1074 \\
\hline SIN1 & $3.25^{\#}(0.023)$ & - & - & $2.24^{\#}(0.008)$ & NM_001009768 & Oar.1093 \\
\hline VDUP1 & - & - & - & $2.46^{\#}(0.007)$ & EE783894 & Oar.12992 \\
\hline OVAR & - & - & $3.06^{*}(0.019)$ & - & NM_001130934 & Oar.13205 \\
\hline MMP7 & - & - & - & $2.60^{*}(0.048)$ & NM_001136491 & Oar.13267 \\
\hline COL1A1 & - & $2.87^{\#}(0.042)$ & $5.90^{\#}(0.036)$ & - & DY492568 & Oar.13279 \\
\hline LDHA & $2.18^{*}(0.030)$ & - & $2.81^{*}(0.030)$ & $2.12^{\#}(0.026)$ & EE751721 & Oar.13281 \\
\hline PRKAR1A & - & - & $2.57^{*}(0.039)$ & - & NM_001142517 & Oar.13311 \\
\hline CAV1 & - & - & $4.25^{*}(0.013)$ & - & DY493176 & Oar.13316 \\
\hline F11R & - & - & - & $3.56^{*}(0.026)$ & DY502182 & Oar.13343 \\
\hline $\mathrm{HBB}$ & - & - & $5.21^{\#}(0.021)$ & - & DY522642 & Oar.13537 \\
\hline SMCT1 & - & $3.18^{\#}(0.011)$ & - & - & EU048233 & Oar.14460 \\
\hline PPP1R12A & - & $2.42^{\#}(0.022)$ & - & - & EU370548 & Oar.14621 \\
\hline IGFBP-2 & -— & $12.98^{*}(0.038)$ & - & - & NM_001009436 & Oar.15563 \\
\hline HECTD1 & $2.79^{\#}(0.005)$ & - & - & - & EU370535 & Oar.16241 \\
\hline PSMB7 & - & - & $2.46^{\#}(0.027)$ & $4.04^{\#}(0.013)$ & EU366497 & Oar.16276 \\
\hline COL2A1 & $5.10^{\#}(0.019)$ & - & $3.74^{\#}(0.006)$ & - & ACJ06529.1 & Oar.17681 \\
\hline IGF2 & - & $3.64^{\#}(0.042)$ & - & - & NM_001009311 & Oar.376 \\
\hline$I L-1 \beta$ & $5.57^{*}(0.002)$ & $5.55^{*}(0.009)$ & - & - & DY502470 & Oar.434 \\
\hline OXT & - & - & $9.76^{\#}(0.050)$ & - & NM_001009801 & Oar.444 \\
\hline PTGS1 & - & - & $3.67^{\#}(0.030)$ & - & NM_001009476 & Oar.445 \\
\hline TNFa & $4.03^{*}(0.018)$ & $3.52^{*}(0.004)$ & - & - & DY503545 & Oar.455 \\
\hline RAC1 & - & - & - & $2.09^{*}(0.003)$ & EE785210 & Oar.4580 \\
\hline NOD2 & - & - & - & $6.75^{*}(0.046)$ & AM932877 & Oar.4731 \\
\hline FZD3 & - & - & - & $4.05^{*}(0.023)$ & DQ152955 & Oar.4758 \\
\hline NFKBIA & - & - & $3.08^{*}(0.011)$ & $4.15^{*}(0.039)$ & EE815518 & Oar.4761 \\
\hline MIF & - & - & $2.16^{*}(0.050)$ & - & NM_001078655 & Oar.4767 \\
\hline SPRY-4 & - & - & $2.44^{*}(0.040)$ & - & DQ152992 & Oar.4778 \\
\hline TOM & - & $14.37^{\#}(0.020)$ & - & $14.13^{\#}(0.015)$ & NM_001035224 & Oar.4810 \\
\hline TXN & - & - & $2.89^{\#}(0.015)$ & $1.94^{\#}(0.033)$ & NM_001009421 & Oar.482 \\
\hline FN & $3.38^{\#}(0.048)$ & - & $4.65^{*}(0.008)$ & - & FJ234417.1 & Oar.4888 \\
\hline HOXA7 & - & - & - & $2.36^{\#}(0.009)$ & U61979 & Oar.496 \\
\hline CAST & - & - & $2.61^{*}(0.032)$ & $2.35^{*}(0.015)$ & NM_001009788 & Oar.498 \\
\hline ERBA BETA1 & - & $3.52^{*}(0.004)$ & $3.34^{*}(0.010)$ & - & Z68307 & Oar.500 \\
\hline ESR1 & - & - & $68.55^{*}(0.000)$ & - & AY033393 & Oar.505 \\
\hline TNC & $4.82^{*}(0.008)$ & - & $4.56^{\#}(0.004)$ & - & DY475966 & Oar.5104 \\
\hline TNCC2 & - & - & $3.30^{\#}(0.029)$ & - & NM_001112821 & Oar.5156 \\
\hline TF & - & $8.97^{*}(0.023)$ & - & - & EE771342 & Oar.552 \\
\hline CPE & - & - & $3.66^{*}(0.025)$ & - & AF063109 & Oar.622 \\
\hline NOS2 & - & - & $2.28^{*}(0.037)$ & - & AF223942 & Oar.645 \\
\hline
\end{tabular}


Table 3 Different expression of annotated genes between the every two groups (Continued)

\begin{tabular}{ccccccc}
\hline BCAT2 & - & - & - & $2.10^{\#}(0.025)$ & AF050173 & Oar.655 \\
HIF1A & - & - & $2.31^{*}(0.039)$ & $2.35^{\#}(0.030)$ & EE755982 & Oar.6671 \\
FAS & - & - & $3.58^{*}(0.046)$ & $7.19^{*}(0.046)$ & NM_001123003 & Oar.683 \\
CP & - & - & - & $7.91^{*}(0.049)$ & NM_001009733 & Oar.706 \\
DCN & - & - & $3.06^{*}(0.044)$ & - & NM_001009218 & Oar.718 \\
ALDOA & - & - & $2.27^{*}(0.047)$ & - & EE814113 & Oar.733 \\
BBC1 & - & - & $2.03^{*}(0.008)$ & - & EE773437 & Oar.76 \\
FGF10 & - & - & $5.15^{*}(0.032)$ & - & NM_001009230 & Oar.7650 \\
PBR & - & - & $5.35^{*}(0.017)$ & - & NM_001009747 & Oar.779 \\
C-MET & - & - & - & $6.06^{*}(0.037)$ & NM_001111071 & Oar.794 \\
CAT-1 & - & - & $3.31^{*}(0.026)$ & $2.20^{*}(0.041)$ & AF212146 & Oar.798 \\
SFN & - & $2.45^{\#}(0.041)$ & - & - & NM_001009208 & Oar.814 \\
PSMB8 & - & - & $5.58^{*}(0.036)$ & - & NM_001131030 & Oar.8196 \\
CENP-C & $3.38^{*}(0.048)$ & - & - & $2.12^{*}(0.028)$ & U35657 & Oar.847 \\
GRO & - & $3.46^{*}(0.042)$ & - & - & NM_001009358 & Oar.963 \\
IRF2 & - & - & $2.30^{\#}(0.027)$ & - & NM_001009740 & Oar.966 \\
CD40 & - & - & $8.45^{*}(0.047)$ & - & EE821767 & Oar.989 \\
PPARG & - & $3.72^{*}(0.002)$ & - & - & NM_001100921 & Oar.992 \\
\hline
\end{tabular}

Notes:Adult Injury(Al), Adult Control(AC), Neonate Injury(NI), Neonate Control(NC).

*:up-regulation; \#:down-regulation; ( ):P-value; —: no statistical significance $(P>0.05)$.

normal articular cartilage. There are two possible reasons for this finding. First, neonatal cartilage has different gene expression compared with adult cartilage, such as TOM, which may help its self-repair. Second, mechanical injury results in different responses between neonatal and adult cartilage. Our microarray analysis showed that transcripts, including PPAR $\gamma$, HIF1- $\alpha$, and SMAD7, are highly expressed in neonatal injured articular cartilage compared with the adult injury model.

PPARY is expressed in chondrocytes and synoviocytes, and is present and functionally active in human chondrocytes [11]. Consistent with this finding, our study showed PPAR $\gamma$ was up-regulated 3.72-fold in injured neonatal articular cartilage compared with normal articular cartilage, whereas there was no significant difference in expression in the adult sheep injury model. Interestingly, there was also no difference in PPAR $\gamma$ expression in normal adult cartilage compared with neonatal cartilage. These findings suggested that neonatal cartilage showed a strong and unique response to mechanical injury. PPAR $\gamma$ has a significant protective effect and promotes cartilage repair in traumatized chondrocytes by several probable mechanisms. (1) Down-regulation of genes that encode catabolic factors could be involved in this process [20]. PPAR $\gamma$ agonists suppress the expression of inducible nitric oxide synthase and matrix metalloproteinase (MMP)-13 in human chondrocytes, as well as the expression of MMP-1 in human synovial fibroblasts. The inhibition of inducible nitric oxide synthase and MMP-13 induction is PPAR $\gamma$ dependent and occurs at the transcriptional level, probably through repression of NF-kB and AP-1 signaling [20]. The level of phosphorylation of JNK and p38 has also been shown to be diminished in response to specific stimuli in PPAR $\gamma$ deficient mice [21]. (2) Anti-inflammatory effects are considered to mainly exert action through transrepressing proinflammatory genes in a DNA-binding-dependent manner 


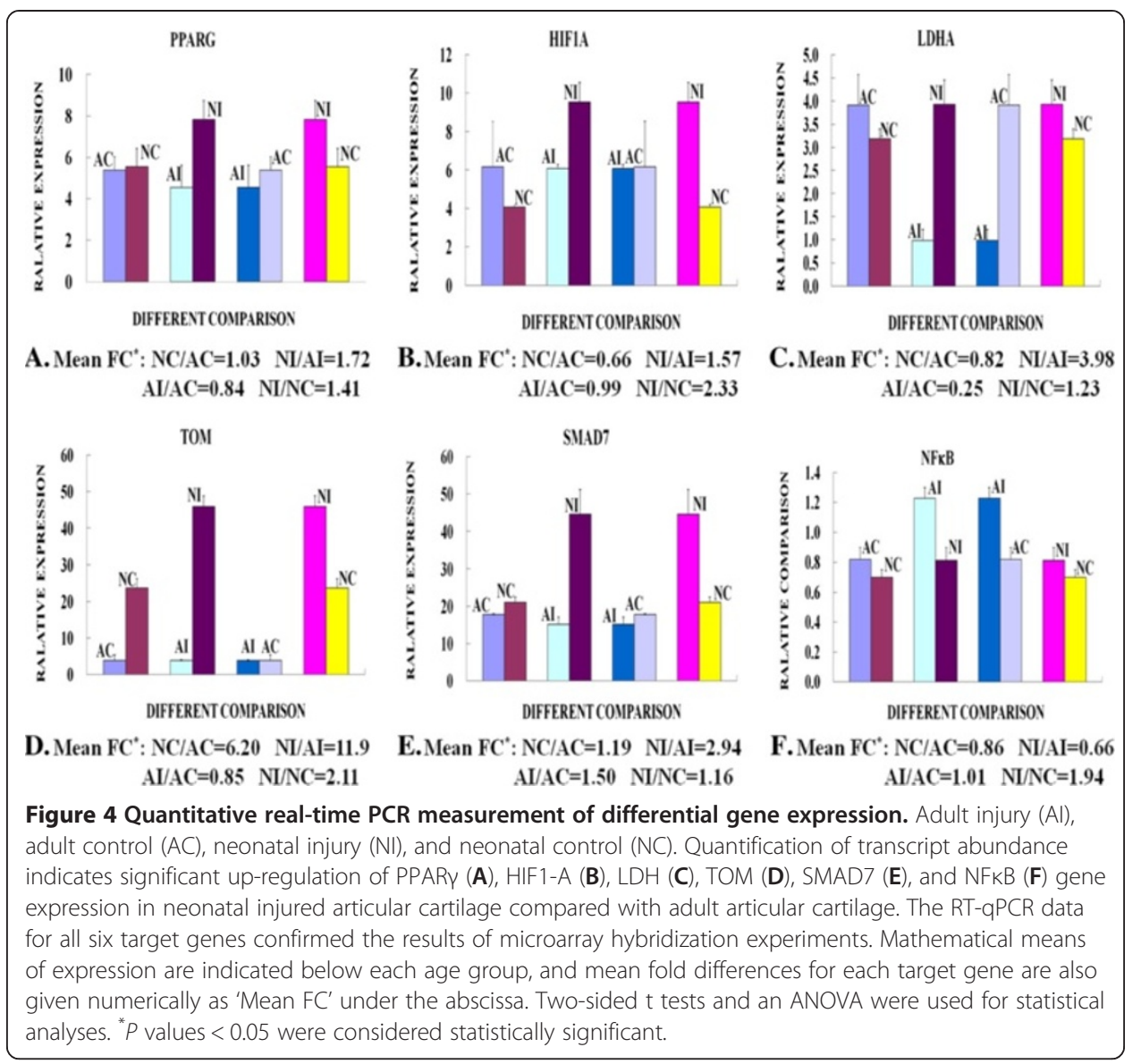

$[22,23]$. Trauma can induce inflammatory responses, and also activate the expression of anti-inflammatory factors synchronously. PPAR $\gamma$ may be a potential therapeutic agent for treating articular cartilage injury and defects. Therefore, further study is required on how to enhance PPAR $\gamma$ expression to promote cartilage repair in adult injured articular cartilage.

To date, TOM is found in several tissues, including epithelia, lungs, and macrophages [12]. To the best of our knowledge, no report describing a protease inhibitor as a cartilage-sparing agent has been published. However, we detected TOM gene expression in ovine articular cartilage. TOM expression was significantly increased in neonatal ovine articular cartilage after acute mechanical injury, with a 14.1-fold increase compared with control adult tissue. However, there was no significant difference in TOM expression in the adult sheep injury model. Interestingly, TOM gene expression was increased 15.73-fold in normal neonatal articular cartilage compared with adult articular cartilage. TOM gene expression has inherently high levels in neonatal ovine articular cartilage, which is beneficial to cartilage repair. In vitro studies have shown that the immobilization of trappin-2/elafin extracellular matrix proteins in articular cartilage plays a protective role by preserving structural integrity of the tissue against damage caused by neutrophilic infiltration during inflammation [24]. Trappin-2 and elafin may promote cartilage repair through their anti-inflammatory activities, which appear to be independent of their anti-elastase activity [25]. All of 
these processes may be involved in the reason for a stronger repair capacity in neonatal articular cartilage than adult cartilage.

Articular cartilage following acute injury results in the activation of a series of signaling responses. In the present study, SMAD7 mRNA in chondrocytes was up-regulated by 2.36-fold in neonatal injured articular cartilage compared with normal articular cartilage. In contrast, SMAD7 was down-regulated 2.04-fold in adult injured articular cartilage compared with the neonate. There was no difference in SMAD7 expression between normal adult and neonatal cartilage. SMAD7 is involved in cell signaling, which is a transforming growth factor $\beta$ (TGF $\beta$ ) type I receptor antagonist. Overexpression of SMAD7 totally prevents TGF $\beta$-induced proteoglycan synthesis in chondrocytes at the mRNA and protein level and completely antagonizes the effects of TGF $\beta$ on proliferation [26]. Therefore, SMAD7 may cause cartilage degeneration and accelerate the response of the injury by inhibiting TGF $\beta$ signaling. SMAD7 acts in a negative feedback loop to inhibit TGF $\beta$ activity because of its interaction with ligandactivated TGF $\beta R I$, and it interferes with the phosphorylation of receptor-associated Smads, preventing nuclear translocation of the activated Smad complexes [27]. The effects of IL-1 $\beta$ on SMAD7 expression in human articular chondrocytes are mediated through the NF- $\mathrm{kB}$ pathway [13]. Interestingly, SMAD7 has been reported to regulate the NF- $\mathrm{kB}$ pathway. SMAD7 is able to block the TGF $\beta$-induced phosphorylation of $\mathrm{I} \kappa \mathrm{B}$, resulting in a decrease in NF- $\kappa \mathrm{B}$ DNA binding [28]. Other studies have indicated that SMAD7 can also act as an NF- $\mathrm{kB}$ activator in some conditions [29]. In addition, a recent study showed that SMAD7 overexpression in transgenic mouse epidermis at levels comparable to those seen in pathological states is insufficient to block TGF $\beta$ or bone morphogenetic protein signaling, but instead produces striking phenotypes due to degradation of $\beta$-catenin through a novel mechanism involving Smad7 and Smurf2 [30].

SMAD7, NF-кB, and TGF $\beta$ pathways play a vital role in articular cartilage development and homeostasis. Therefore, a potential new mechanism for pathway crosstalk has important implications for the understanding of maturation and repair of articular cartilage.

\section{Conclusions}

There are significant differences in gene expression between neonatal and adult ovine articular cartilage following acute injury. These differences are partly due to intrinsic differences in the process of development and partly to different biological responses to mechanical trauma between neonatal and adult articular cartilage. Of these, PPAR $\gamma$ and TOM could be novel target molecules and potential chondroprotective agents involved in cartilage injury and complete repair.

\footnotetext{
Abbreviations

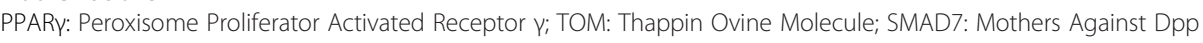
(Drosophila) Human Homolog 7; NF-kB: Nuclear Factor-Kappa B; HIF1-a: Hypoxia Inducible Factor 1a; LDH: Lactate Dehydrogenase; GAPDH: Glyceraldehyde-3-Phosphate Dehydrogenase; COL2A1: Collagen Type li; TNC: Tenascin-C; COL1A1: Collagen Type I; IL-1ß: Interleukin 1 $\beta$; GROa: Growth-Regulated Oncogene a; MSCs: Mesenchymal Stem Cells; MMP-13: Matrix Metalloproteinase-13; TGFß: Transforming Growth Factor B.
}

The authors declare that they have no conflict of interests related to this work. 
the article: XX, QZ, HW. Critical revision of the article for important intellectual content: XX, QZ, HW. Final approval of the article: XX, QZ, HW, LZ, PL. Statistical analysis: XX, HW, QZ. Administrative, technical, or logistic support: HW, QZ, LZ, PL. Collection and assembly of data Acquisition of data: XX, HW, LZ, PL. All authors read and approved the final manuscript

\section{Acknowledgements}

This work was supported by the National Natural Science Foundation of China (30872622). Technical assistance in Microarray experiments was provided us with by KangChen Bio-tech, Shanghai, China.

Received: 11 March 2013 Accepted: 10 June 2013

Published: 17 June 2013

\section{References}

1. Schulze-Tanzil G: Activation and dedifferentiation of chondrocytes: implications in cartilage injury and repair. Ann Anat 2009, 191(4):325-338.

2. Chan PS, Schlueter AE, Coussens PM, Rosa GJ, Haut RC, Orth MW: Gene expression profile of mechanically impacted bovine articular cartilage explants. J Orthop Res 2005, 23(5):1146-1151.

3. Mienaltowski MJ, Huang L, Frisbie DD, Mcllwraith CW, Stromberg AJ, Bathke AC, et al: Transcriptional profiling differences for articular cartilage and repair tissue in equine joint surface lesions. BMC Med Genomics 2009, 2:60.

4. Messner $\mathrm{K}$, Maletius W: The long-term prognosis for severe damage to weight-bearing cartilage in the knee: a 14-year clinical and radiographic follow-up in 28 young athletes. Acta Orthop Scand 1996, 67(2):165-168.

5. Shapiro F, Koide S, Glimcher MJ: Cell origin and differentiation in the repair of full-thickness defects of articular cartilage. J Bone Joint Surg Am 1993, 75(4):532-553.

6. Namba RS, Meuli M, Sullivan KM, Le AX, Adzick NS: Spontaneous repair of superficial defects in articular cartilage in a fetal lamb model. J Bone Joint Surg Am 1998, 80(1):4-10

7. Dell'Accio F, De Bari C, Eltawil NM: Identification of the molecular response of articular cartilage to injury, by microarray screening: Wnt-16 expression and signaling after injury and in osteoarthritis. Arthritis Rheum 2008, 58(5):1410-1421.

8. Frisbie DD, Bowman SM, Colhoun HA, DiCarlo EF, Kawcak CE, Mcllwraith CW: Evaluation of autologous chondrocyte transplantation via a collagen membrane in equine articular defects: results at 12 and 18 months. Osteoarthr Cartil 2008, 16(6):667-679.

9. Feldman AL, Costouros NG, Wang E, Qian M, Marincola FM, Alexander HR, et al: Advantages of mRNA amplification for microarray analysis. Biotechniques 2002, 33(4):906-912. 914.

10. Benjamini $Y$, Hochberg $Y$ : Controlling the false discovery rate: apractical and powerful approach to multiple testing. J Roy Stat Soc 1995, B:289-300.

11. Giaginis C, Giagini A, Theocharis S: Peroxisome proliferator-activated receptor-gamma (PPAR-gamma) ligands as potential therapeutic agents to treat arthritis. Pharmacol Res 2009, 60(3):160-169.

12. Guyot N, Zani ML, Maurel MC, Dallet-Choisy S, Moreau T: Elafin and its precursor trappin-2 still inhibit neutrophil serine proteinases when they are covalently bound to extracellular matrix proteins by tissue transglutaminase. Biochemistry 2005, 44(47):15610-15618.

13. Baugé C, Attia J, Leclercq S, Pujol JP, Galéra P, Boumédiene K: Interleukin-1 beta up-regulation of Smad7 via NF-kappaB activation in human chondrocytes. Arthritis Rheum 2008, 58(1):221-226.

14. Smith GD, Knutsen G, Richardson JB: A clinical review of cartilage repair techniques. J Bone Joint Surg Br 2005, 87(4):445-449.

15. Eltawil NM, De Bari C, Achan P, Pitzalis C, Dell'accio F: A novel in vivo murine model of cartilage regeneration Age and strain-dependent outcome after joint surface injury. Osteoarthr Cartil 2009, 17(6):695-704.

16. Wang Y, Ding C, Wluka AE, Davis $S$, Ebeling PR, Jones $G$, et al: Factors affecting progression of knee cartilage defects in normal subjects over 2 years. Rheumatology (Oxford) 2006, 45(1):79-84.

17. Lee JH, Fitzgerald JB, Dimicco MA, Grodzinsky AJ: Mechanical injury of cartilage explants causes specific time-dependent changes in chondrocyte gene expression. Arthritis Rheum 2005, 52(8):2386-2395.

18. Mienaltowski MJ, Huang L, Stromberg AJ, MacLeod JN: Differential gene expression associated with postnatal equine articular cartilage maturation. BMC Musculoskelet Disord 2008, 9:149.

19. Geyer M, Grässel S, Straub RH, Schett G, Dinser R, Grifka J, et al: Differential transcriptome analysis of intraarticular lesional vs intact cartilage reveals new candidate genes in osteoarthritis pathophysiology. Osteoarthr Cartil 2009, 17(3):328-335

20. Fahmi H, Di Battista JA, Pelletier JP, Mineau F, Ranger P, Martel-Pelletier J: Peroxisome proliferator-activated receptor gamma activators inhibit interleukin-1 beta-induced nitric oxide and matrix metalloproteinase 13 production in human chondrocytes. Arthritis Rheum 2001, 44(3):595-607.

21. Kobayashi T, Notoya K, Naito T, Unno S, Nakamura A, Martel-Pelletier J, et al: Pioglitazone, a peroxisome proliferator-activated receptor gamma agonist, reduces the progression of experimental osteoarthritis in guinea pigs. Arthritis Rheum 2005, 52(2):479-487.

22. Rizzo G, Fiorucci S: PPARs and other nuclear receptors in inflammation. Curr Opin Pharm 2006, 6:421-427.

23. Belvisi MG, Hele DJ, Birrell MA: Peroxisome proliferator-activated receptor gamma agonists as therapy for chronic airway inflammation. Eur J Pharmacol 2006, 533(1-3):101-109.

24. Zani ML, Nobar SM, Lacour SA, Lemoine S, Boudier C, Bieth JG, et al: Kinetics of the inhibition of neutrophil proteinases by recombinant elafin and pre-elafin (trappin-2) expressed in Pichia pastoris. Eur J Biochem 2004, 271(12):2370-2378

25. Guyot N, Butler MW, McNally P, Weldon S, Greene CM, Levine RL, et al: Elafin, an elastase-specific inhibitor, is cleaved by its cognate enzyme neutrophil elastase in sputum from individuals with cystic fibrosis. J Biol Chem 2008, 283(47):32377-32385 
26. Scharstulh $A$, Diepens $R$, Lensen J, Vitters $E$, van Beunigen $H$, Van der Kraan $P$, et al: Adenoviral overexpression of Smad-7 and Smad-6 differentially regulates TGF-beta-mediated chondrocyte proliferation and proteoglycan synthesis. Osteoarthr Cartil 2003, 11(11):773-782.

27. Moustakas A, Souchelnytskyi S, Heldin CH: Smad regulation in TGF- $\beta$ signal transduction. J Cell Sci 2001, 114 (Pt 24):4359-4369.

28. Grau AM, Datta PK, Zi J, Halder SK, Beauchamp RD: Role of Smad proteins in the regulation of NF-KB by TGF- $\beta$ in colon cancer cells. Cell Signal 2006, 18(7):1041-1050.

29. Monteleone G, Mann J, Monteleone I, Vavassori P, Bremner R, Fantini M, et al: A failure of transforming growth factor- $\beta 1$ negative regulation maintains sustained NF-kB activation in gut inflammation. J Biol Chem 2004, 279(6):3925-3932.

30. Asano Y, Ihn H, Yamane K, Kubo M, Tamaki K: Impaired Smad7-Smurf-mediated negative regulation of TGF-beta signaling in scleroderma fibroblasts. J Clin Invest 2004, 113(2):253-264.

doi:10.1186/1475-925X-12-53

Cite this article as: Xue et al: Different responses to mechanical injury in neonatal and adult ovine articular cartilage. BioMedical Engineering OnLine 2013 12:53.

\section{Submit your next manuscript to BioMed Central and take full advantage of:}

- Convenient online submission

- Thorough peer review

- No space constraints or color figure charges

- Immediate publication on acceptance

- Inclusion in PubMed, CAS, Scopus and Google Scholar

- Research which is freely available for redistribution 